
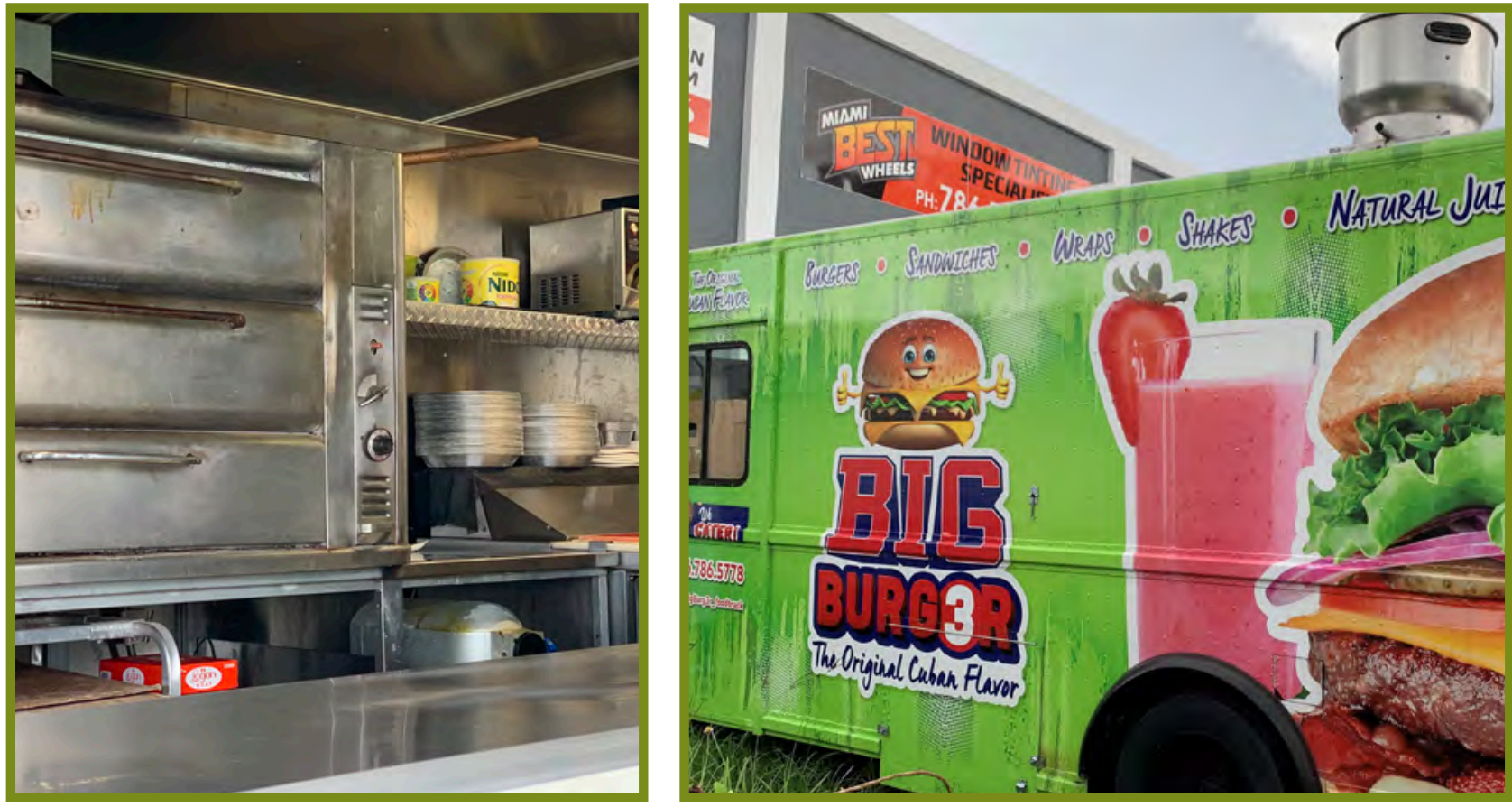

\title{
Exploring Food Truck Food Safety Training and Practices in the United States: A Qualitative Study
}

\section{ABSTRAGT}

The food truck industry is rapidly growing, and yet the policies governing this segment of the food service industry are inconsistent or lack enforcement. This study explored food truck owners' and managers' attitudes toward food safety training, the challenges of providing food safety training, and the preferred food safety training methods. The study also investigated food safety practices and concerns specific to the food truck sector. A qualitative study utilizing focus groups and individual faceto-face interviews with food truck owners and managers from several cities in the United States (i.e., Atlanta, Birmingham, Miami, and San Francisco] was conducted. The results showed that ServSafe was the most used food safety training method. Food safety training was viewed as necessary and essential for a food truck business. The food truck owners and managers perceived time, money, and lack of appropriate facilities as barriers to providing training to their employees. The food truck owners and managers were open minded in incorporating helpful tools and/or methods to assist their efforts in food safety training. Several food safety challenges specific to food truck operations were related to pest control, storage, temperature control, handwashing, and equipment. The results also suggested that food trucks operators need innovative training methods and assistance to alleviate food safety challenges.

\section{INTRODUCTION}

The U.S. Centers for Disease Control and Prevention (CDC) estimates that 76 million people suffer from foodborne illnesses each year in the United States (40). Foodborne illnesses also accounted for 325,000 hospitalizations and more than 5,000 deaths in 2018 (40). The CDC reports that three pathogens, namely, Salmonella, Listeria, and Toxoplasma, are the primary pathogens responsible for 75 percent of the reported illnesses and 1,500 deaths (40). The U.S. Department of Agriculture (USDA) Economic Research Service reports an even higher incidence of these types of illnesses. According to USDA Economic Research Service reports, there are 48 million estimated cases of foodborne illnesses related to 
microbial pathogens, with 1,400 deaths linked to foodborne pathogens each year $(38,39)$. In addition, foodborne illnesses can create tremendous economic costs. It is estimated that foodborne illnesses cost more than $\$ 15.5$ billion each year (40).

Statistics show that most of the reported foodborne illnesses are caused by food service establishments (15, 20). Further investigations of the factors that led to these foodborne illnesses revealed that the majority of these cases were associated with improper cooling, reheating, and holding of foods, inadequate cooking of foods to the minimum recommended temperature, and lapses of 12 or more hours between preparation and eating. Furthermore, the purchasing and receipt of foods from unsafe sources, cross-contamination of equipment and utensils, and poor personal hygiene of restaurant employees also contributed to foodborne illnesses $(5,21,40)$.

The typical food delivery outlets, such as commercial restaurants, are now competing with a significant escalation of mobile food vendors $(19,26)$. In 2019, food truck revenue reached $\$ 1$ billion dollars in the United States, with close to 24,000 food trucks in operation (19). Despite their popularity, food trucks face more food safety challenges than the traditional brick and mortar establishments due to the nature of the business. In 2016, 9 of 96 licensed food trucks in Boston were closed after "on the spot" inspections had revealed food safety hazards (49).

The environment of a mobile food establishment may not be ideal in providing personal hygiene accommodations; for instance, food trucks may not be equipped with a suitable sink, clean water, and hand soap for handwashing. Additionally, they also lack hot water that reaches $100^{\circ} \mathrm{F}$ for handwashing (30). A study conducted by Chukuezi (4) showed that street food vendors washed their utensils in dirty or recycled water when clean water was not accessible. Furthermore, the lack of restroom facilities, proper plumbing, and pest control are also challenges that food truck operators face (30). Food trucks may lack facilities for proper refrigeration. El-Shenawy et al. (12) have found that food items that were stored in the food trucks, such as processed cheese and eggs, were kept at inappropriate temperatures. Additionally, the close quarters and limited storage space on a food truck may limit the correct methods of storage for cleaning agents or other types of chemicals (46). Vendors may potentially serve high volumes of consumers at the same time, which, as shown by previous research $(13,17)$, can also lead to lower standards of food safety practices.

Food safety training is one of the plausible ways to improve food safety knowledge and practices among food handlers and improve the food safety inspection scores of restaurants $(8,21,25,36)$. Food service workers who are knowledgeable about food safety and can correctly practice food safety skills are critical in the prevention of foodborne illnesses. Previous literature has identified various barriers in carrying out the proper training of food handlers in restaurants, including time restraints, poor attitude and food safety knowledge among food handlers, and limited access to appropriate resources $(3,10,36)$. Limited studies have investigated food safety training in the food truck industry.

While commercial restaurants are regulated by specific food safety guidelines, the nature of a food truck lends itself to distinctive policies adapted to the unique way the food is prepared and served. However, there is no uniform policy in the United States that stipulates how food truck management secures licensing or food safety certification or the extent of food safety training for the parties involved (48). Before any recommendations can be made to improve food handling practices among food truck vendors, more research needs to be done to gather a more holistic picture of food handling practices by food truck vendors and their current food safety training needs. Therefore, the objective of this qualitative study was to explore food truck owners' and managers' attitudes toward food safety training, the challenges of providing food safety training, and the preferred food safety training methods. The study also investigated food safety practices and concerns unique to the food truck business.

\section{MATERIALS AND METHODS}

The study protocol (13-407 EP 1402) was approved by the Institutional Review Board (IRB) at Auburn University, in the state of Alabama.

\section{Sampling}

Both focus groups and individual face-to-face interviews were used for data collection to gather a wide array of insights from the food truck owners and managers. To be considered for the focus groups and face-to-face interviews, the food truck operation needed to be in business for at least 5 years, thereby demonstrating both sufficient experience and success in operating the food trucks.

\section{Focus groups}

Academia has seen an increasing use of focus group interviews in research because of its ability to bring forward spontaneous and expressive views by the research participants on a particular subject (23). This study adopted this approach and used a nondirective style of interviewing to encourage a variety of viewpoints $(23,34)$. Through county websites, the locations of 150 food trucks were identified in Alabama, Georgia, and Florida. A random cluster sampling approach was used to narrow the sample to 50 food truck owners and managers. Each of these food truck owners and managers received an initial information letter from the researchers. The participants who responded and agreed to participate were sent several emails to 
confirm their availability. The focus groups then took place at a hotel conference center convenient to the majority of the participants.

\section{Face-to-face interviews}

In addition to focus groups, face-to-face interviews were conducted with owners and managers of food trucks to gather a wider array of viewpoints. These food truck owners and managers who participated in the present study were from the following major cities: Atlanta, GA; Birmingham, AL; Miami, FL; and San Francisco, CA. The majority of these cities were chosen as they have food truck associations; San Francisco was included because the city is an established food truck municipality. Websites of the food truck associations contain details regarding the association's mission, sponsored events, and contact information regarding the food truck members. The researchers first browsed through these websites and contacted the potential participants via email. Next, one of the researchers traveled to the sites of the food trucks to interview the owners and managers who agreed to participate in the interviews.

\section{Data collection for focus groups and face-to-face interviews}

The questions for focus groups and face-to-face interviews were developed based on previous literature on food safety, food truck laws and regulations, and food safety training programs $(1,16)$. Questions were identical for all the participants. The questions were reviewed for content validity by three experts in the food service industry and then pilot tested for clarity with two food truck owners; these two owners did not participate in the final study.

Semistructured interviews were used for final data collection both for focus groups and face-to-face interviews. Semistructured interviews allowed the researchers to ask the predetermined set of questions. However, this method also allowed the participants to provide trajectory information that strayed away from the preset questions if they felt such information was relevant (7). Examples of the predetermined questions included participants' thoughts and opinions towards food safety training (i.e., general attitudes, challenges, and training methods) and food safety practices in the food truck setting. Table 1 presents the questions asked during the semistructured interviews. Before data collection started, all participants completed a consent form and were assigned pseudonyms. Each focus group lasted an average of $35 \mathrm{~min}$, while each interview lasted an average of $18 \mathrm{~min}$. All sessions were audio recorded for transcribing.

\section{Data analysis}

Data gathered from focus groups and face-to-face interviews were transcribed by the researchers. The information was then uploaded to the qualitative data analysis software program, ATlas.ti. Miles and Huberman (28) pointed out that computer-aided analysis can make procedures more systematic, ensure completeness and refinement, and increase reliability. The researchers then read through the transcriptions to develop a list of tentative codes for each of the interview and focus group questions. "Coding" is a process of aggregating and categorizing text in order to identify different themes (28). This process is common in qualitative research and is used to avoid data overload and allow a greater focus on answering the targeted research questions (28). The "families" editing option then created axial codes at the second level of coding. Axial codes are defined as "passages identified by a user-defined set of codes representing concepts from the data that were in common" (14). From this point, coding subthemes were developed by consolidation of second-level codes by the researchers.

\section{RESULTS}

\section{Demographics of the participants}

A total of 21 food truck owners and managers participated in the five focus groups. Each focus group consisted of four to five participants. Fifteen participants (71.4\%) were owners of the food trucks, and the remaining $6(28.6 \%)$ were food truck managers. Each participant has worked in other areas of the food and beverage sector, including restaurants, catering, and dining services in hospitals.

A total of 25 face-to-face interviews were conducted in four different cities as follows: Birmingham, $\operatorname{AL}(n=5)$; Miami, FL ( $n=5)$; San Francisco, CA $(n=5)$; and Atlanta, GA $(n=10)$. This sample included managers $(n=15)$ and owners $(n=10)$ that have been operating in the food truck industry for at least five years. The trucks operated by these owners and managers were part of a franchise $(60 \%)$ or independently owned (40\%). Sixty percent of these owners and managers have other food service experience in addition to the food truck sector, while forty percent have worked exclusively in the food truck sector.

\section{Food safety training: certifications, attitudes, and methods}

All focus group participants indicated that they had received prior food safety training. However, only 17 $(80.9 \%)$ of them had provided food safety training to their employees, mostly through ServSafe training. Maintaining an up-to-date food safety certification and recertification were viewed as important to the participants as food truck owners and managers. However, they felt that it was not their responsibility to keep up to date with food safety certification and training. Four participants (19\%) mentioned that it should be up to the city to provide notification as to when certification for training is necessary and when to attend the training sessions. 


\section{TABLE 1. Focus group and interview questions}

\begin{tabular}{|c|c|}
\hline Topics & Questions \\
\hline \multirow{12}{*}{$\begin{array}{l}\text { Current practices } \\
\text { of food safety } \\
\text { training }\end{array}$} & Would you share some of your thoughts regarding food safety training? \\
\hline & Have you ever worried about a foodborne illness outbreak due to lack of training? Why or Why not? \\
\hline & Have you worked in other areas of food service? If yes, which area? \\
\hline & What areas of food safety need more attention in a food truck setting? \\
\hline & What specific food safety measures are different in a food truck setting? \\
\hline & What kind of training do you provide? How frequent? \\
\hline & Do you keep up to date with food safety laws and regulations? How often? \\
\hline & Do you keep up to date with mandatory food safety certifications? How often? \\
\hline & $\begin{array}{l}\text { What type of food safety training do you and your employees participate in? Is this type of training you } \\
\text { provide required by law or mandatory? Who provided the training? How long did the training last? } \\
\text { (if the training was provided by themselves) }\end{array}$ \\
\hline & What made you qualified to train your employees on the topic of food safety? \\
\hline & What food safety topics did you cover in the food safety training you provided? \\
\hline & Where did you receive the information and training materials to conduct the training? \\
\hline \multirow{4}{*}{ Attitude } & Is food safety training important to you? Why or why not? \\
\hline & Do you feel confident that your customers are not worried about the safety of your product? \\
\hline & Do you feel competent in providing food safety training to your employees? \\
\hline & Are you confident in passing inspections from country health officials? Which areas concern you and your staff? \\
\hline \multirow{7}{*}{$\begin{array}{l}\text { Specific food } \\
\text { safety measures }\end{array}$} & In your experience, which food safety violations have you seen being committed on a food truck? \\
\hline & What specific areas need more attention when compared to general food safety? \\
\hline & Which food safety practices have you spent time correcting? \\
\hline & $\begin{array}{l}\text { If you were to consult someone on operating a food truck what would you suggest the food safety training } \\
\text { focus on? }\end{array}$ \\
\hline & $\begin{array}{l}\text { What do you think are important topics to be included in food safety training when training food truck } \\
\text { employees? }\end{array}$ \\
\hline & Do you feel that your general food safety training is sufficient for a food truck environment? \\
\hline & What training techniques would I witness during your food safety training? \\
\hline
\end{tabular}

Of the 25 food truck owners and managers who were interviewed face-to-face, 20 (80\%) were ServSafe certified either through the 8 -h classroom training $(75 \%)$ or the online training $(25 \%)$. All participants stated that they followed training requirements set forth in their respective city, where in each of the cities represented by the interviewees, a manager on duty is required to complete ServSafe or the Certified Food Safety Manager program.

\section{Attitudes towards food safety training}

Participants in the focus groups revealed their attitude toward food safety training. As Table 2 shows, food safety training was viewed as a necessary aspect of the industry and an essential phase of the operation of a food truck business, even though a few of the participants regarded it as "something that is not enjoyable." Participants who have received food safety training commented that the training has boosted their confidence in serving safe food to their customers. Three participants (14.3\%) further indicated that they have confidence in their chefs and their personal skills to perform proper food handling practices because they have been trained in this aspect. None of the participants felt that they should conduct extra training other than what the city or county mandated.

Food truck owners and managers in the face-to-face interviews discussed the completion of the required training in their individual cities. One participant commented that food safety training was not necessary because his business has never had a food safety violation during the inspection. Similarly to the focus group 


\section{TABLE 2. Attitudes of food truck managers/owners toward food safety training}

\begin{tabular}{|c|c|}
\hline Themes & Selected Quotes \\
\hline \multirow{3}{*}{ Confidence } & $\begin{array}{l}\text { FG1: "The training I have received from ServSafe is researched and proven so I am confident they } \\
\text { taught me what I need." }\end{array}$ \\
\hline & $\begin{array}{l}\text { FG22: "I am confident in my chefs and handpicked them. They feel their culinary school experience has } \\
\text { trained them properly." }\end{array}$ \\
\hline & FG14: "I am confident in handling food safely due to my culinary school experience." \\
\hline \multirow{5}{*}{ Training necessity } & FG13: "I am not interested but the training is a necessary." \\
\hline & FG25: "The training is needed because everyone thinks running a food truck is the new money maker." \\
\hline & FG16: "(The training is) needed to keep guest's safe from people with no training." \\
\hline & FG18: "Training is necessary to keep consumers safe from non-educated cooks." \\
\hline & $\begin{array}{l}\text { FI10: “... we have never been given a violation so I don't feel the need to spend money and time on } \\
\text { training when we have not had any violations." }\end{array}$ \\
\hline $\begin{array}{l}\text { Minimum requirement } \\
\text { of city/county }\end{array}$ & $\begin{array}{l}\text { FI1: "My truck follows the required regulations in the areas we operate and none of those areas stated } \\
\text { that we have to do extra training." }\end{array}$ \\
\hline
\end{tabular}

Notes: FG, focus groups; FI, face-to-face interviews.

participants, none of the participants would go above and beyond the minimum training requirements set forth by their city or county.

\section{Challenges for providing food safety training}

In the focus group sessions, time was discussed (23\%) and determined to be a major issue related to food safety training provisions. One manager who utilized ServSafe as a training method stated that "The training is time consuming and it cost the loss of a whole day."

The need for monetary resources was discussed by four food truck owners and managers (16\%) during the faceto-face interviews as a barrier to training employees on a monthly basis. The lack of adequate facilities is an additional setback that was identified as a barrier to providing training on a monthly schedule. For example, one participant stated, "I have no location to have my staff all be in the same place." It was mentioned by 15 (71.4\%) food truck owners and managers in the face-to-face interviews that the physical layout of the truck also added to the problem of conducting the training sessions (e.g., "The layout of a food truck makes it a problem to train, it is way too tight for employees to be cramped in there to train..."). Owners and managers that prepared food in a commissary kitchen stated that they did not want to pay extra out of their pockets to use or rent the kitchen for training purposes.

\section{Food safety training methods}

In addition to ServSafe training either through traditional classroom or online settings, other training methods used by the participants in the focus groups to expose their employees to food safety training included role-play and onthe-job-training. As seen in Table 3, the participants in the focus groups felt that time-saving solutions for training were needed so that they would be more motivated to implement the training on a regular basis. It was mentioned by two participants that having a smartphone or tablet application would be something that they could incorporate into their training for menu planning and cooking. Additionally, the participants in the focus groups discussed the use of visual aids on the food truck as a training method.

Food truck owners and managers in the face-to-face interviews revealed similar opinions on the training methods, with one of them specifically commenting on the lack of food safety apps that facilitated the process of getting certified. Another interviewee discussed the value of "mock situations" so that employees are more exposed to various scenarios related to food safety. A few participants further discussed the importance of utilizing role-play techniques before each shift or lineup. Role-playing prior to beginning a shift brings greater awareness and reinforcement in the execution of safety practices by the employees, according to one participant.

\section{Food truck food safety practices and concerns: Equipment}

The participants in the focus group sessions were asked to discuss their views on the aspects of food safety practices and concerns that are specific to the mobile food environment. As Table 4 shows, equipment was discussed 
TABLE 3. Gurrent and preferred food safety training methods of the food truck owners and managers

\begin{tabular}{|c|c|}
\hline Themes & Selected Quotes \\
\hline \multirow{4}{*}{$\begin{array}{l}\text { Role play/ mock } \\
\text { situation }\end{array}$} & FG18: "I do a role play and I pretend as if I'm the inspector." \\
\hline & FG5: "We have meetings and I'll role-play or ask questions." \\
\hline & FI3: "We role play on communication it's vital in the tiny environment." \\
\hline & $\begin{array}{l}\text { FII7: "Communication is something that should be focused on, in that tight of an environment something } \\
\text { can go wrong if staff is not trained. A mock situation in my experience works well when enhancing training } \\
\text { experience of the staff." }\end{array}$ \\
\hline \multirow[b]{2}{*}{ On-the-job training } & FG21: "I train my staff on cooking techniques and how to cook my food." \\
\hline & $\begin{array}{l}\text { FI3: "I think my staff should have training topics every day. This will keep them always thinking about food } \\
\text { safety. I show them new recipes and I think throwing in a little lesson weekly would keep them informed." }\end{array}$ \\
\hline \multirow{3}{*}{ Smartphone app } & FG20: "An app of some sort from ServSafe would be useful and save time." \\
\hline & $\begin{array}{l}\text { FG2: "Time is valuable since everyone has a smartphone or tablet it makes sense for us to have an app. } \\
\text { That would make life easier they could log on take the exam and done." }\end{array}$ \\
\hline & $\begin{array}{l}\text { FI6: "Since time is always valuable and everyone has a smartphone or tablet, I'm surprised there is not a } \\
\text { food safety app. This would make life a lot easier have my employees log on take the exam and complete } \\
\text { the certification." }\end{array}$ \\
\hline \multirow{3}{*}{ Visual aids } & FG5: "Visualize processes like handwashing." \\
\hline & $\begin{array}{l}\text { FG9: "I think visual charts are helpful for temperatures, I use them to remind them if I'm not there } \\
\text { for plating." }\end{array}$ \\
\hline & FI8: "Pictures can remind staff of what to do." \\
\hline
\end{tabular}

Notes: FG, focus groups; FI, face-to-face interviews.

(66.6\%), with particular attention to the temperature of the equipment, which includes ensuring that the (cooking and refrigeration) equipment is able to reach correct temperatures and maintain those temperatures $(23 \%)$, and modifying equipment to fit the needs of a food truck business (8\%). During the discussion, participants mentioned that, depending on the type of food served or the previous use of the truck, equipment changes or modifications were inevitable. One example brought up in the discussion was an old ice cream truck that needed an equipment modification because it would be used to serve hot food items (e.g., "We serve crepes so we had to modify the electric to have enough power to operate with the coolers since our truck was an old ice cream truck").

When discussing the food safety practices and concerns in regard to food trucks, the participants discussed the modifications made to their kitchen equipment in order to conform to their own operation. The cleanliness of equipment was discussed by five interviewees $(20 \%)$. The cleanliness of the immediate area outside a food truck was deemed an important consideration as well. It was noted by one respondent that consumers view the cleanliness of the outside of the truck when choosing which truck to purchase food from, just as a consumer would not choose a restaurant with an undesirable appearance.

Food truck food safety practices and concerns: Cleaning

In addition, cleaning was found to be a critical measure in operating a food truck. Cleaning (57\%) was an important aspect due to the mobile nature of the food service and the occasional storage of food outdoors. The participants discussed that food trucks that are not properly cleaned after each service and leave food residue would draw pests. Furthermore, the cleaning of cooking equipment (41.6\%) was identified as a challenge. In some instances, the appropriate room for a dishwasher is not available or the power supply to support a dishwasher is lacking. Another challenge identified was the lack of time to wash pots and pans by hand, as the customers expected to receive their food in a short amount of time. One participant commented that his food truck has extra equipment on board in order to avoid the extra cleaning work on the food truck. Participants also noted that they have to be careful when cleaning the pots and pans on the food trucks to avoid cross-contamination, since dirty, contaminated pots and pans can be in close proximity to the food being served. 


\section{TABLE 4. Food truck food safety practices}

\begin{tabular}{|c|c|}
\hline Themes & Selected Quotes \\
\hline \multicolumn{2}{|l|}{ Cleaning } \\
\hline Pest problems & $\begin{array}{l}\text { FI6: "Every time after we are open I clean the outside of the truck so that we are always ready. I think } \\
\text { that this will also help keep pests away..." }\end{array}$ \\
\hline Dishwashing & $\begin{array}{l}\text { FG17: "There is no dishwasher like a restaurant kitchen, so having enough pots and pans is important, } \\
\text { as we can't really hand wash them in time when serving food." }\end{array}$ \\
\hline Contact surfaces & FG14: "Contamination of surfaces with collecting money, cards and then serve food." \\
\hline $\begin{array}{l}\text { Storage of cleaners/ } \\
\text { chemicals }\end{array}$ & $\begin{array}{l}\text { FG23: "The layout and space of the truck makes it difficult to properly store chemicals and a lot of the } \\
\text { times I keep them off the truck." }\end{array}$ \\
\hline \multicolumn{2}{|l|}{ Handwashing } \\
\hline Water temperature & FI15: "Enough power to heat water for handwashing." \\
\hline Time to wash hands & FG25: "If I am busy with a line I can't walk off the truck to wash my hands." \\
\hline Public restrooms & FG19: “The good areas to sell usually not within the 200-ft. requirement to use public restrooms.” \\
\hline Use of hand sanitizer & FI10: "In some areas, only hand sanitizer is required." \\
\hline \multicolumn{2}{|l|}{ Equipment } \\
\hline Equipment modification & $\begin{array}{l}\text { FI9: "The biggest modification was making our fryer able to fit inside of our truck. It was hand welded } \\
\text { together and works perfect." }\end{array}$ \\
\hline $\begin{array}{l}\text { Temperature of the } \\
\text { equipment }\end{array}$ & $\begin{array}{l}\text { FI1: "Since we serve crepes we had to modify the electric so that we could have enough power to } \\
\text { operate along with the coolers since we bought our truck from an old business that served ice cream." } \\
\text { FG8: "Generator at certain sizes can't run a cooler, flat top and water heater for handwashing." }\end{array}$ \\
\hline Power/gas safety & $\begin{array}{l}\text { FI17: "Power safety is important since I personally have been cited by the fire department. They inspect } \\
\text { trucks in my area." }\end{array}$ \\
\hline \multicolumn{2}{|l|}{ Permits } \\
\hline Multiple permits & $\begin{array}{l}\text { FI19: "It is not necessary to obtain different permits for different areas. Unfortunately, due to the nature } \\
\text { of the business, it's what we have to deal with. It is our responsibility as owners to keep up with the ever- } \\
\text { changing laws." } \\
\text { FG16: "Business license, parking and about fifty other permits you need but a few places nothing about } \\
\text { food safety." }\end{array}$ \\
\hline Up-to-date & $\begin{array}{l}\text { FI7: "Keeping up to date with permits, many trucks let their certifications expire and serve where they } \\
\text { will not get ticketed." }\end{array}$ \\
\hline Enforcement & $\begin{array}{l}\text { FI15: "I travel mostly to food truck events and take care of the permits and most of the time inspectors } \\
\text { are not going to come out during very busy periods." }\end{array}$ \\
\hline \multicolumn{2}{|l|}{ Inspections } \\
\hline Fire department & FI5: "Fire department regularly inspects our gas and electric to ensure safety." \\
\hline Commissary kitchen & FI20: "Commissary kitchens are inspected and I could get in trouble for something I didn't do." \\
\hline Location & $\begin{array}{l}\text { FG14: "If not inspected every year its owner's responsibility to let health inspector know where they } \\
\text { are located." }\end{array}$ \\
\hline
\end{tabular}

Note: FG, focus groups; FI, face-to-face interviews.

\section{Food truck food safety practices and concerns: Handwashing}

Another important concern related to food safety of food trucks that was discussed was handwashing (61\%).
Several issues relevant to handwashing that were discussed by the participants included water temperature, lack of time to wash hands, using hand sanitizer instead of soap, and running out of water or soap on the truck. Two 
managers discussed an example of their circumstances. In their service location, the law states that food trucks are only required to park within two hundred feet of a public restroom and are not required to have a handwashing sink on the truck. Therefore, this particular regulation poses a challenge to park close enough to a public restroom and allow employees ample time to be able to walk off the truck and wash their hands. Some participants (14\%) have come up with another solution, which is to allow their employees to use hand sanitizer instead of washing their hands.

\section{Food truck food safety practices and concerns: Permits}

The discussion by five of the participants further emphasized the issue of permits and licenses (20\%). The participants stated that it was a struggle to meet the regulations while operating within multiple municipalities; therefore, the preference is to operate in a municipality with less stringent regulations. In addition, several cities and communities within a county have different criteria in issuing a permit, making it difficult to run a food truck while being in compliance with all mandated rules. Many municipalities have enforced heavy fines on food truck operators who failed to follow rules of obtaining permits, which is discouraging to owners. Several participants (20\%) discussed the lack of city or county health officials who inspect their food trucks on a regular basis. In this case, a fire department was mentioned by owners and managers as the entity that does the inspection on food trucks.

\section{DISCUSSION}

Food truck operations continue to grow throughout the United States, but evidence showed that many food trucks violated critical control points that contributed to foodborne illnesses (46). Consequently, a proactive approach in the awareness and prevention of foodborne illness in this sector of the food service industry is needed. This study explored food safety training in the food truck industry, including the food truck owners' and managers' attitudes toward food safety training, the challenges to training, and the current and preferred training methods. This study also sought to identify food safety practices and concerns specific to the food truck sector.

ServSafe is a food safety certification program commonly used by the participants. However, the majority of municipalities only accept the ServSafe course certification administered in a classroom setting (11), which the participants found to be an inconvenience. Attending ServSafe is sometimes considered a hardship, as it not only may reduce business revenue but is perceived by the participants to be costly. The participants indicated that they only went through recertification every five years, as required by the law.

The attitudes of food service operators towards food safety has a significant impact on the food safety culture with reference to the operations and implementation of food safety programs (18). Previous research has shown that positive management attitudes towards food safety training provided employees assurance to perform their job correctly, which could result in decreasing the number of foodborne illnesses $(2,13,22,24,29)$. Roberts and Barrett (35) found that restaurant managers realize the benefits of food safety training, including how it may ensure that safe food is served to customers, maintain the reputation of their operations, and increase their employees' awareness towards food safety protocol. The findings of the present study supported the value of food safety training as a means to increase the confidence, knowledge, and skills of food handlers to provide and serve safe food to their customers.

The participants utilized various food safety training methods in their food truck operations, including roleplay, mock situations, and on-the-job training. Training approaches such as these are conducted on-site and have been found to improve knowledge retention (47) while reducing costs related to time. The study found that participants were interested in a food safety app that allows training access via a smartphone or tablet. Due to the mobile nature of the food truck operation, a food safety app would offer food truck operators greater flexibility to train their employees. Such a potential app may alleviate the issue of time restraint and allow employees to quickly access food safety information and refresh their knowledge at their convenience. Additionally, participants used visual aids to emphasize and reinforce food safety awareness with their employees. Visual aids are useful reminders that operators can post to foster food safety practices (40). Food safety apps and visual aids that are user-friendly and tailored to the needs of the food truck industry may be created to increase food safety training about food truck operation.

The participants in this study indicated that attention needs to be paid to several food safety practices unique to food truck operations, concerning such topics as cleaning, handwashing, equipment, permits, and inspections, concerns which were consistent with previous literature (30, 31, 41, 46). Regarding cleaning, participants commented that thorough cleaning of food trucks is important to keep pests away. Several cities or counties have taken extra effort to prevent issues with pests. The cities of Denver, CO, and Los Angeles, CA, and the District of Columbia require food trucks to have a permanent sliding screen on their serving window in order to keep pests from entering the truck $(5,7,9,11)$. The storage of materials and placement of items is another critical facet of food safety. Food trucks have limited space, thereby posing a dilemma in finding adequate storage for necessary materials. One participant stated, "The layout of the truck and space make storing of chemicals a challenge." Another participant commented, "Unlike a restaurant that can have a dedicated room, we have to ensure it is safe on the truck." According 
to the FDA Food code, chemical substances used for cleaning and maintenance must be stored away from food $(43,44)$, which could be a challenge for food trucks with limited space. A carefully designed layout in the food truck is crucial to maximize the use of limited space.

Handwashing remains another top food safety concern. For example, it is difficult to maintain the proper temperature of water for handwashing. Many food truck operations depend on an electric generator to power equipment and to heat water to the necessary temperature for the requirements in food preparation. As stated by one participant, "Generator at certain sizes can't run a cooler, flat top and water heater for handwashing." Because of this, many participants opted to use hand sanitizer for hand cleaning, even though hand sanitizer is not a suitable substitute for handwashing. The FDA Food Code (42, 43, 44) states that hands must be washed at a temperature of $100^{\circ} \mathrm{F}$ and specifies that the use of hand sanitizer may be applied in addition to handwashing. Participants were aware of these requirements but stated that they could not always be in compliance with these standards, which is similar to findings by Samapundo et al. (37) that showed proper handwashing did not always occur. Moreover, outdoor environments can create a problem when addressing the handwashing requirement due to the lack of running water on food trucks, as well as having the proper water temperature for handwashing and sanitizing utensils and cookware $(27,32,46)$. As stated in previous studies, handwashing is a critical area to be emphasized because of its value in reducing foodborne illness $(15,17)$.

Equipment modification was another unique area identified by the food truck owners and managers as essential to the food truck sector. A few participants indicated that they modified equipment to meet the needs of their business, even though the modification may not meet the approved standards set by the FDA. In certain locations where food trucks operate, the food preparation and cooking equipment in the food trucks must be inspected by the fire department. The fire department will take notice of any defects in the modified equipment, but not a health inspector. Because of this, the modified equipment may not meet the food safety requirements for equipment, such as reaching the correct temperature for handwashing, coolers holding the right temperature for cold food, or heating food to the proper temperature (31). Additionally, an increase in self-modified equipment causes concern in the area of fire safety. The lack of standards and ineffective inspections is a public safety concern because food truck explosions from propane tanks have occurred in several cities in the United States, especially for those trucks that are unlicensed and have modified equipment (32). Regular inspection and monitoring from both health inspectors and fire marshals are recommended to make sure the modified equipment meets the standards to reduce food safety issues and fire hazards.
The power supply on a food truck is a unique challenge that is not guaranteed as the vehicles could be on the move and must solely rely on the generators (31). This could increase the risk of foodborne illness, as statistics showed that food trucks with malfunctioning refrigeration units and improper handwashing were major causes of foodborne illness $(24,31,46)$.

The present study revealed that routine inspections in the food truck sector are not being performed regularly. The mobile nature of a food truck makes it difficult for health inspectors to locate the food truck while it is in operation. Locating the food trucks is a time-consuming process which adds additional work hours for health inspectors (46). On average, brick and mortar businesses are inspected every 6 months by the health department (44). However, food trucks may not be inspected with the same frequency; in fact, in the present study, a few participants stated that they have yet to be inspected by health inspectors. This finding was similar to previous research by Vanschaik and Tuttle (46). These investigators found that the food trucks were inspected when they were not in operation, and therefore, it was not possible to evaluate food and water safety risk factors associated with the food trucks. Routine inspections are necessary in order to protect the general public from health risks, and if food safety violations are reported, further investigations should take place to determine the root cause of these violations.

\section{Limitations and recommendations for future research}

The limitations of the study include the following. The majority of the participants in the focus group interviews were from the southeastern region of the United States, and the participants in the face-to-face interviews were from four cities (i.e., Atlanta, Birmingham, Miami, and San Francisco). Due to geographical limitations and lack of consistency in the laws in the food truck sector throughout the country (48), the results of the study should be cautiously generalized beyond this geographic region. Future studies may include food truck owners and managers from a broader geographical base in order to gain a larger perspective concerning the issues related to food safety training and practices in this sector of the food service industry. In addition, the sample size was small because some food truck operators did not provide their correct contact information on the websites, or their business operation may have been suspended during the data collection period. Future studies may utilize a different sampling method, such as snowball sampling, to recruit more participants. It should be noted that certification of food safety was self-reported. Even though focus groups and face-to-face interviews provide the advantage of allowing researchers to observe social cues and body language of the interviewees (34), the results of this study may be affected by social desirability. A future study may include 
an observational approach in order to verify the food safety practices as reported by the participants.

\section{CONCLUSIONS}

The food truck business has been growing at a rate of $6.8 \%$ annually from 2014 to 2019 (19). In 2019, food truck operations generated a total revenue of $\$ 1$ billion (19). Research studies in this type of food service point out the need for improvement in food safety practices among food truck operators in order to prepare and serve safe food to the public $(15,46)$. The responses in the current study indicated that previous food safety training was received by all participating owners and managers. ServSafe certification was the most popular instructive means from which owners and managers received their training. The current study identified several challenges that food truck operators face when providing food safety training, including lack of time, sufficient funds, and accommodating facilities. These barriers to providing proper and adequate food safety training need to be addressed to ensure that the public is protected against foodborne illnesses. Several preferred training methods and solutions were identified that may assist in alleviating the challenges involved. The use of a smartphone or tablet app, appropriate visual aids, or creative role-play activities can serve as useful training methods. Barriers to providing proper food safety training occur in food service, and incorporating these suggested practices may help alleviate some of these barriers. The main themes identified by the participants in this study that relate to food safety practices were cleaning, equipment, handwashing, inspections, and permitting. Policy makers should pay attention to these areas of concern, making sure new rules and regulations are enacted and implemented to reduce the risks of foodborne illness in the food truck industry.

\section{REFERENCES}

1. Adrendt, S., W. Palez, and C. P. Strohbehn. 2013. Food safety practices and managers' perceptions: a qualitative study in hospitality. Int. J. Contemp. Hosp. Manage. 25:124-139.

2. Angelillo, I. F., N. M. A. Viggiani, L. Rizzio, and A. Bianco. 2000. Food handlers and foodborne diseases: knowledge, attitudes and reported behavior in Italy. J. Food Prot. 63:381-385.

3. Bush, D., L. Paleo, R. Baker, R. Dewey, N. Toktogonova, and D. Cornelio. 2009. Restaurant supervisor safety training: evaluating a small business training intervention. Publ. Health Rep. 124:152-159.

4. Chukuezi, C. O. 2010. Food safety and hygienic practices of street food vendors in Owerri, Nigeria. Stud. Sociol. Sci. 1:50-57.

5. City and County of Denver, Department of Environmental Health. No date. Mobile retail food truck, trailer, and cart guide. Available at: https://www.denvergov.org/content/ dam/denvergov/Portals/771/documents/ PHI/Food/Mobile\%20Unit\%20Guide.pdf. Accessed 5 May 2020

6. Clayton, D., and C. Griffith. 2004. Observation of food safety practices in catering using notational analysis. Brit. Food J. 106:211-227.

7. Cohen, D., and B. Crabtree. 2006. Qualitative research guidelines project. Available at: http://www.qualres.org/HomeSemi-3629. html. Accessed 20 March 2020.

8. Cotterchio, M., J. Gunn, T. Coffill, P. Tormey, and M. A. Barry. 1998. Effect of a manager training program on sanitary conditions in restaurants. Publ. Health Rep. 113:353-358.

9. County of Los Angeles Public Health. 2017. Mobile food facility plan check guidelines. Available at: http://www. publichealth.lacounty.gov/eh/docs/ Plan_Check/ MFFPlanCheckGuide.pdf. Accessed 5 May 2020.
10. da Cunha, D. T., E. Stedefeldt, and V. Vera de Rosso. 2014. The role of theoretical food safety training on Brazilian food handlers' knowledge, attitude and practice. Food Control 43:167-174.

11. District of Columbia Department of Consumer and Regulatory Affairs. 2017. Mobile food truck licensing information. Available at: https://dchealth.dc.gov/ publication/ mobile-food-vending. Accessed 4 May 2020.

12. El-Shenawy, M., M. El-Shenawy, J. Manes, and J. M. Soriano. 2011. Listeria spp. in street-vended ready-to-eat-foods. Interdiscip. Perspect. Infect. Dis. 2011:968031.

13. Ghezzi, S., and B. Ayoun. 2013. Food safety in the U.S. catering industry: empirical findings. Int. J. Contemp. Hosp. Manage. 25:365-382.

14. Gibbs, G. R. 2002. Qualitative data analysis: explorations with NVivo. Open University Press, Buckingham, United Kingdom.

15. Green, L. R., and C. Selman. 2003. Factors impacting food workers' and managers' safe food preparation practices: a qualitative study. Food Prot. Trends 25:981-990.

16. Hawk, Z. 2013. Gourmet food trucks: an ethnographic examination of Orlando's food truck scene. University of Central Florida, Orlando, FL. Available at: https://sciences. ucf.edu/anthropology/wp-content/uploads/ sites/19/2013/09/ Hawk_Zachart.pdf. Accessed 5 May 2020.

17. Hertzman, J., and D. Barrash. 2007. An assessment of food safety knowledge and practices of catering employees. Brit. Food J. 109:562-576.

18. Howes, M., S. McEwen, M. Griffiths, and L. Harris. 1996. Food handler certification by home study: measuring changes in knowledge and behavior. Dairy Food Environ. Sanit. 16:737-744.
19. IBISWorld. 2019. Food trucks industry in the U.S.-market research report. Available at: https://www.ibisworld.com/industry/foodtrucks.html. Accessed 3 May 2020.

20. Jones, T., B. Imhoff, M. Samuel, P. Mshar, K. McCombs, M. Hawkins, V. Deneen, M. Cambridge, and S. Olsen. 2004. Limitations to successful investigation and reporting of food-borne outbreaks: an analysis of foodborne disease outbreaks in FoodNet catchment areas, 1998-99. Clin. Infect. Dis. 38:S297-S302.

21. Kneller, P., and T. Bierma. 1990. Food service certification: measuring the effectiveness of a state program. J. Environ. Health 52:292-294.

22. Ko, W. H. 2013. The relationship among food safety knowledge, attitudes and self-reported HACCP practices in restaurant employees. Food Control 29:192-197.

23. Kvale, S., and S. Brinkman. 2009. Interviews: learning the craft of qualitative research interviewing. Sage Publications, Thousand Oaks, CA.

24. Liu, S. Z. Liu, H. Zhang, L. Lu, J. Liang, and Q. Huang. 2015. Knowledge, attitude, and practices of food safety amongst food handlers in the coastal resort of Guangdong, China. Food Control 47:457-461.

25. McElroy, D. M., and C. N. Cutter. 2004. Self-reported changes in food safety practices as a result of participation in a statewide food safety certification program. Food Prot. Trends 24:150-161.

26. McLaughlin, K. 2009. Food truck nation. Available at: https://www.wsj.com/articles/ SB100014240529702044566045742019340 18170554. Accessed 4 May 2020.

27. Mercer, M. 2017. To keep on trucking, states streamline food truck licensing. Available at: http://www.pewtrusts.org/en/researchand-analysis/blogs/stateline/2017/04/18/ to-keep on-trucking-states-streamline-foodtruck-licensing. Accessed 13 May 2020. 
28. Miles, M. B., and M. A. Huberman. 1986. Qualitative data analysis: a sourcebook of new methods. Educ. Eval. Policy Anal. 8:329-331.

29. Nee, O. S., and A. N. Sani. 2011. Assessment of knowledge, attitudes and practices (KAP) among food handlers at residential colleges and canteen regarding food safety. Sains Malays. 40:403-410.

30. Novis, D. 2017. Food truck food safety. Available at: https://www. foodqualityandsafety. com/article/foodtruck-food-safety/. Accessed 5 May 2020.

31. Okumus, B., and S. Sonmez. 2019. An analysis on current food regulations for and inspection challenges of street food: case of Florida. J. Culin. Sci. Technol. 17:209-223.

32. Okumus, B., S. Sonmez, S. Moore, D. P. Auvil, and G. D. Parks. 2019. Exploring safety of food truck products in a developed country. Int. J. Hosp. Manag. 81:150-158.

33. Olsen, S., L. MacKinon, J. Goulding, N. Bean, and L. Slutsker. 2000. Surveillance for foodborne disease outbreaks - United States, 1993-1997. Morb. Mortal. Wkly. Rep. 49:1-15.

34. Opdenakker, R. 2006. Advantages and disadvantages of four interview techniques in qualitative research. Qual. Social Res. 7:1-13.

35. Roberts, K. R., and B. B. Barrett. 2011. Restaurant managers' beliefs about food safety training: an application of the theory of planned behavior. J. Foodserv. Business Res. 14:206-225.

36. Roberts, K. R., B. B. Barrett, A. D. Howells, C. W. Shanklin, V. K. Pilling, and L. A. Brannon. 2008. Food safety training and employees' knowledge and behaviors. Food Prot. Trends 28:252-260.
37. Samapundo, S. R., Climat, R. Xhaferi, and F. Devlieghere. 2015. Food safety knowledge, attitudes, and practices of street food vendors and consumers in Port-au-Prince, Haiti. Food Control 50:457-466.

38. Scallan, E., R. M. Hoekstra, F. J. Angulo, R. V. Tauxe, M. Widdowson, S. L. Roy, and P. M. Griffin. 2011. Foodborne illness acquired in the United States-major pathogens. Emerg. Infect. Dis.17:7-15.

39. U.S. Department of Agriculture, Economic Research Service. 2015. Economic burden of major foodborne illness acquired in the United States. Available at: https://www.ers. usda.gov/publications. Accessed 1 May 2020.

40. U.S. Department of Health and Human Services, Centers for Disease Control and Prevention. 2018. CDC and food safety. Available at: https://www.cdc.gov/ foodsafety/pdfs/CDC-Food-Safety-2018-H. pdf. Accessed 1 May 2020.

41. U.S. Food and Drug Administration. 2000. Report of the FDA retail food program database of foodborne illness risk factors. Available at: https://wayback. archive-it.org/7993/20170406023019/ https://www.fda.gov/downloads/Food/ GuidanceRegulation/UCM123546.pdf. Accessed 1 May 2020.

42. U.S. Food and Drug Administration. 2009 FDA report on the occurrence of foodborne illness risk factors in selected institutiona foodservice, restaurant, and retail food store facility types. Available at: http:// www.foodprotect.org/issues/packets/ 2012ScribePacket/attachments/I_024_b. pdf. Accessed 1 May 2020.
43. U.S. Food and Drug Administration. 2009. Food code 2009. Available at: https:// www.fda.gov/food/fda-food-code/foodcode-2009. Accessed on 1 May 2020.

44. U.S. Food and Drug Administration. 2013 Food code 2013. Available at: https:// www.fda.gov/food/fda-food-code/foodcode-2013. Accessed on 1 May 2020.

45. U.S. Food and Drug Administration. 2017. Food code 2017. Available at: https:// www.fda.gov/food/fda-food-code/foodcode-2017. Accessed on 1 May 2020.

46. Vanschaik, B., and J. Tuttle. 2014. Mobile food trucks: California EHS-net study on risk factors and inspection challenges. J. Environ. Health 76:36-37.

47. Walter, A., N. L. Cohen, and R. C. Swicker. 1997. Food safety training needs exist for staff and consumers in a variety of communitybased homes for people with developmental disabilities. J. Am. Diet. Assoc. 97:619-625.

48. Williams, C. 2013. A hungry industry on rolling regulations: a look at food truck regulations in cities across the United States. Maine Law Rev. 65:706-717.

49. Woolhouse, M., and M. Rocheleau. 2017. A major issue for some Boston food trucks? Handwashing. Available at: https://www. boston.com/news/business/2017/06/04/amajor-issue-for-some-boston-food-truckshand-washing. Accessed 5 May 2020. 